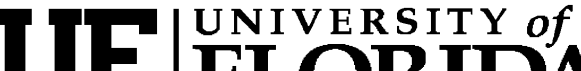 FLORIDA \\ IFAS Extension
}

\section{Characterization of the "Strawberry Dried Calyx Disorder" in Florida and Spain 1}

\section{Bielinski M. Santos, Craig K. Chandler, Alicia J. Whidden, and María del Carmen Sánchez²}

The strawberry dried calyx disorder (SDCD) has been observed since 2005 in farms around Plant City, Florida and Huelva, Spain. This disorder starts as a slight darkening of newly opened and already formed flowers (Figure 1), resembling salt injury, and then progresses towards calyx burning, and fruit discoloration and deformation (Figure 2). Field surveys performed in both locations during the 2005-06, 2006-07, and 2007-08 seasons suggest that certain strawberry cultivars are more susceptible than others to the appearance of SDCD.

In Florida, strawberries are planted in open fields, while in Spain they are produced exclusively under high tunnels, mini-tunnels, and passively ventilated greenhouses. In both countries, growers plant several cultivars concurrently to achieve continuous fruit production by overlapping cultivar production peaks. Cultivars undergo equal irrigation, fertilization, and pest management programs all season long. Field observations indicated the cultivars 'Strawberry Festival', 'Camino Real', and 'Palomar' showed the SDCD earlier and more severely than others.
More detailed surveys conducted in Spain during the 2007-08 season confirmed that out of the 16 farms visited, representing about 2500 ha $(38 \%$ of all the planted area in Spain), 15 experienced moderate to severe SDCD symptoms. These symptoms consistently developed after exposure to stressful conditions, such as low temperatures and/or light. Regardless of the production system, the symptoms appeared to be associated with high electric conductivity (EC; salt concentration) of hydroponic media (perlite or coconut fiber mix) or soil. In those farms with the highest incidence of SDCD, it was common to find soil EC values at or higher than 0.3 $\mathrm{mS} / \mathrm{cm}$ and as high as $0.75 \mathrm{mS} / \mathrm{cm}$. Only moderate SDCD was associated with EC soil values below 0.2 $\mathrm{mS} / \mathrm{cm}$. As expected, soil texture also plays a major role in allowing salt "washing" away from the root zone. At one farm with both sandy and loamy soils and under the same fertigation programs, batches of cultivars planted in sandy soil had about $30 \%$ fewer affected plants than those planted in heavier soils.

In Florida, SDCD has been observed mainly in 'Strawberry Festival' fields within 10 days after a freeze or after nights with very low temperatures

1. This document is HS1134, one of a series of the Horticultural Sciences Department, Florida Cooperative Extension Service, Institute of Food and Agricultural Sciences, University of Florida. Original publication date February 2008. Visit the EDIS Web Site at http://edis.ifas.ufl.edu.

2. Bielinski M. Santos and Craig K. Chandler, assistant professor and professor, respectively, Gulf Coast Research and Education Center; Stephen M. Olson, professor, North Florida Research and Education Center; Alicia J. Whidden, extension agent, Hillsborough County Extension Service, Cooperative Extension Service, University of Florida, Gainesville, FL 32611; and María del Carmen Sánchez, EMCO CAL EU Variety Expert. 
$\left(36^{\circ} \mathrm{F}=3^{\circ} \mathrm{C}\right.$ or less) and where very aggressive fertilization programs with poor irrigation and drainage are used. Growers with farms affected with SDCD have reduced the incidence of the disorder by providing only irrigation water or reducing fertilizer use during the 3 or 4 days before and after a stressful event (e.g. a freeze).

The effect of the type of protective structure was assessed in 2007 on a strawberry farm in Huelva, Spain. Plants of 'Strawberry Festival' were set between October 4 and 6 under three types of protective structures: low tunnels $(9.5 \mathrm{ft}$ high $=2.85$ $\mathrm{m})$, high tunnels $(11 \mathrm{ft}$ high $=3.30 \mathrm{~m})$, and passively-ventilated greenhouses $(16 \mathrm{ft}$ high $=4.80$ $\mathrm{m})$. These structures were covered with the same polyethylene plastic covers, which reduced photosynthetic active radiation by $40 \%$. Plants in all three structures had the same growing substrate (perlite), and received the same fertilization and irrigation programs and crop management throughout the season. The EC of the nutritional solution at the injection points was $1.6 \mathrm{mS} / \mathrm{cm}$, while it was 1.7 $\mathrm{mS} / \mathrm{cm}$ at the drainage points.

The temperatures at the center of each structure measured at 3:00pm CET were 77, 72.5, and $67^{\circ} \mathrm{F}$ $\left(25.0,22.5,19.5^{\circ} \mathrm{C}\right)$, respectively. However, approximately 13 weeks after transplanting, six samples of 75 plants within each structure (450 plants per structure) were randomly assessed for SDCD incidence, regardless of the severity of the damage. The data revealed that there were significant differences in the number of plants with SDCD. Strawberries in low tunnels had the lowest number of plants with SDCD symptoms (8.9\%), followed by those in the high tunnels (14.5\%), and by those in the greenhouses $(23.2 \%)$. Therefore, it appears that SDCD problems increased as the temperature decreased.

Another test was conducted in 2006 at the Gulf Coast Research and Education Center, IFAS, University of Florida under greenhouse conditions using six strawberry cultivars. Mature plants of 'Strawberry Festival', 'Winter Dawn', 'Camarosa', 'Camino Real', 'Treasure', and '00-51' were transplanted in sand culture under greenhouse conditions to determine whether the SDCD could be reproduced in isolated conditions. Plants were irrigated three times per week with nutritive solutions containing $0,0.6,1.2,2.4$, and $4.8 \mathrm{mS} / \mathrm{cm}$ and the incidence of SDCD was monitored twice weekly by counting the number of affected plants. Symptoms of salt injury (similar to those observed in farms) developed at 30 days in 'Strawberry Festival' and 'Camino Real' with the $1.2 \mathrm{mS} / \mathrm{cm}$ solution (Figure 3 ), whereas the other cultivars did not show visible injury. The remaining cultivars developed salt damage at 45 and 55 days after initial treatment of 1.2 and $2.4 \mathrm{mS} / \mathrm{cm}$ solutions. These preliminary observations indicated that both 'Strawberry Festival' and 'Camino Real' appeared to be more sensitive to high-EC fertilizer solutions than the others.

Circumstantial evidence seems to eliminate biotic entities (i.e. fungi, bacteria, viruses and nematodes) as the causal agents of SDCD because: a) symptoms comparable to SDCD were developed under pathogen-free greenhouse conditions; b) none of the analyzed calyx samples from Florida and Spain with SDCD has yielded positive pathogen results; c) SDCD tends to disappear during the growing season when either fertigation practices are modified or stressful conditions disappear; and, d) SDCD distribution in high tunnels and fields seems to be more accentuated in rows closer to entrances and at the end of drip lines.

Until the nature of this disorder is fully understood, strawberry growers should exercise caution in their fertilization and irrigation programs during stressful environmental conditions for susceptible cultivars. Reducing the fertilization rates during the days before an expected freeze while maintaining regular irrigation programs appears to help to minimize the incidence of SDCD. 


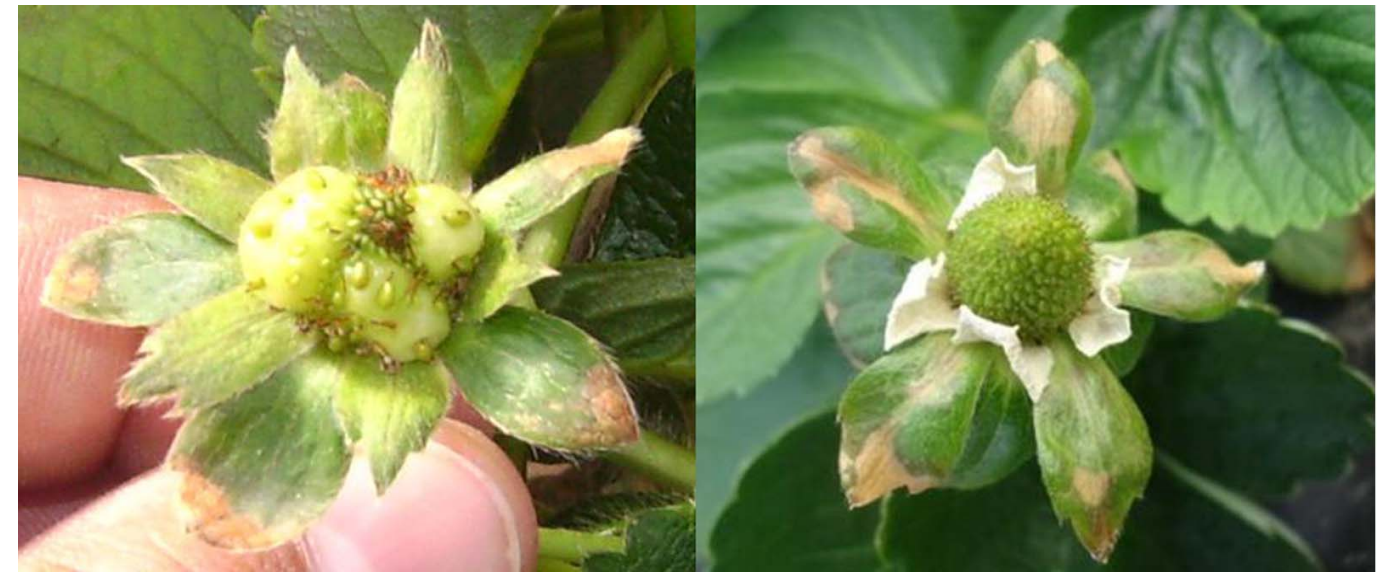

Figure 1. Strawberry dried calyx disorder in immature fruit and flower. Huelva, Spain, 2008. Credits: B.M. Santos

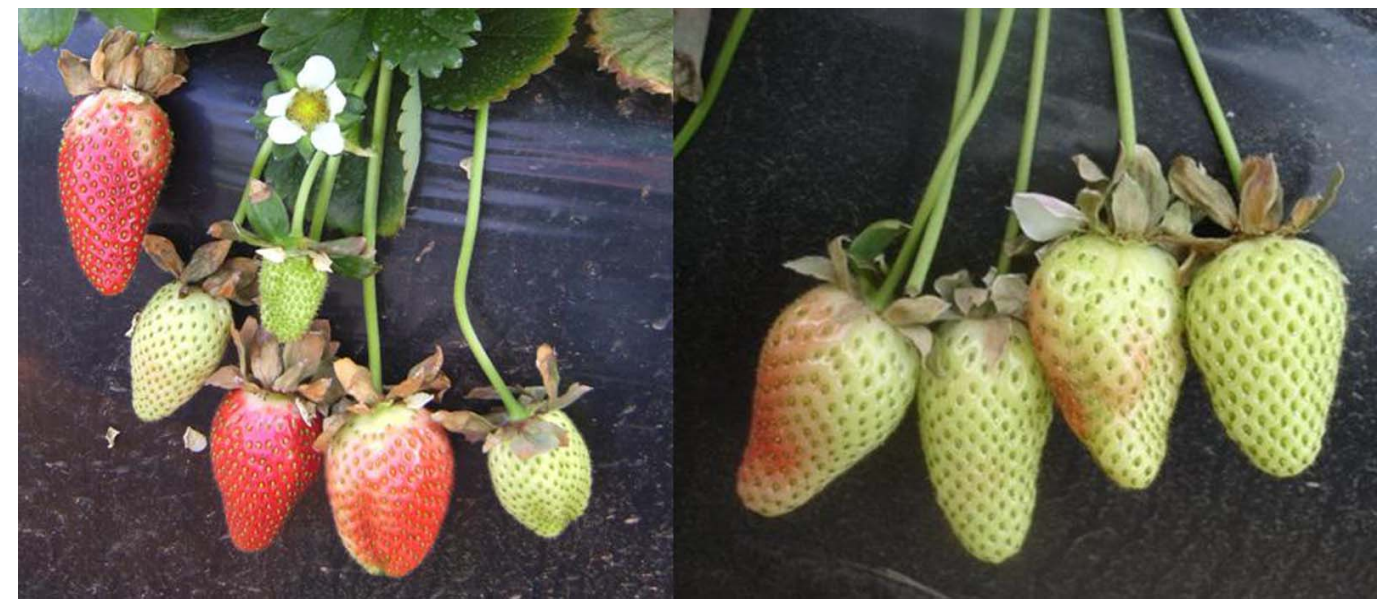

Figure 2. Strawberry dried calyx disorder in mature fruit. Huelva, Spain, 2008. Credits: B.M. Santos

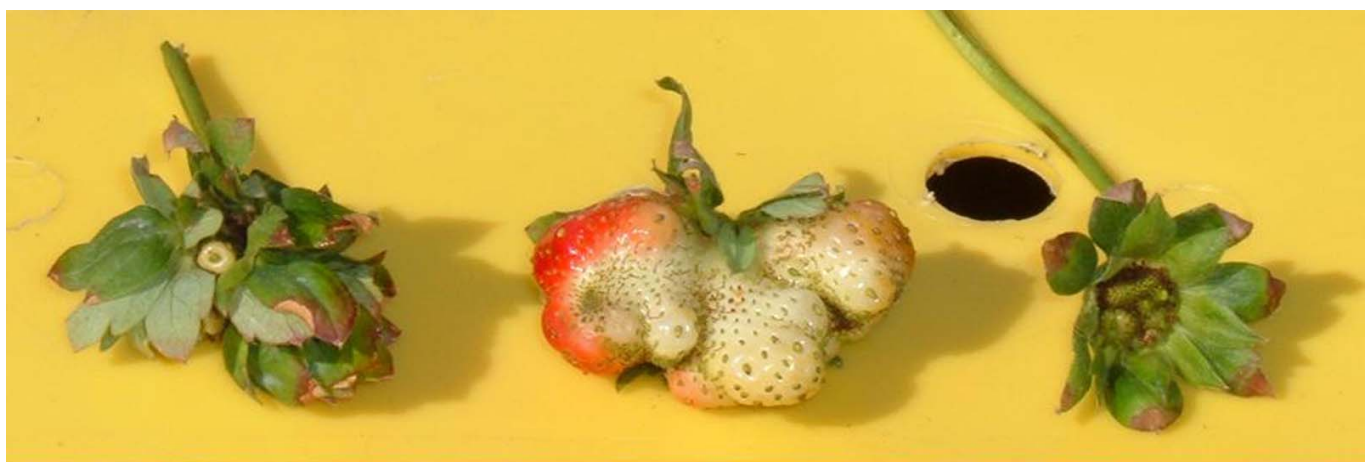

Figure 3. Strawberry dried calyx disorder reproduced under greenhouse conditions. Balm, Florida, 2007. Credits: B.M. Santos 